\title{
Induction de nécroses foliaires, de protéines $b$ et de résistance dans les interactions tabac
} Phytophthora

\author{
Philippe BONNET, Alain POUPET, Pierre ABAD, Paul VENARD \& Loïc CARDIN \\ I.N.R.A., Station de Pathologie végétale, Centre de Recherches d'Antibes, B.P. 2078, F 06606 Antibes Cedex
}

Des tiges de plants de tabac décapités (var. « Xanthi nc » ou "Samsun nn », âgés de 50 à 65 j) ont été soit inoculées avec différentes espèces de Phytophthora soit traitées par dépôt d'une goutte $(20 \mu 1)$ de filtrats de culture obtenus à partir de ces diverses espèces.

Avec 6 espèces de Phytophthora incompatibles (différentes de l'espèce pathogène $P$. parasitica var. nicotianae) on a pu induire la production de protéines additionnelles solubles de type protéine $b$ dans les feuilles de tabac "Xanthi nc » soit après inoculation, $4 \mathrm{j}$ auparavant, par les différentes souches, soit après apport des filtrats de culture correspondants. Ces protéines b, extraites, mises en évidence par électrophorèse sur gel d'acrylamide et immunoélectrophorèse (sérum anti-protéines b isolées de "Xanthi nc " inoculé par le VMT) et dosées par H.P.L.C., présentent des caractéristiques semblables (identité de Rf, parenté sérologique, temps de rétention en H.P.L.C.) à celles obtenues dans la combinaison incompatible -hypersensible : VMT - tabac "Xanthi nc »; par contre, ce type de protéines n'a pu être détecté lorsque l'inoculation est faite avec les diverses souches (ou filtrats de culture) de l'espèce pathogène, $P$. parasitica var. nicotianae. Des essais, en nombre plus limité, effectués avec la var. "Samsun nn " ont abouti à des conclusions voisines : induction de protéines b, forte avec souches ou filtrats d'espèces incompatibles, faible ou nulle avec l'espèce pathogène. Toutefois, la cinétique de production de la protéine bl durant les $15 \mathrm{j}$ suivant l'infection montre, dans le cas de l'interaction non compatible, une accumulation rapide dans les premiers jours, suivie d'une décroissance progressive 8 à $15 \mathrm{j}$ après inoculation ; dans l'interaction compatible ce type de protéines apparaît également, mais faiblement et tardivement.

On a pu montrer, d'autre part, que le pré-traitement de plants de tabac var. "Xanthi nc " par certaines souches incompatibles de Phytophthora (ou par leurs filtrats de culture) était susceptible d'induire un certain degré de protection vis-à-vis d'une inoculation ultérieure par la souche parasite ; il se traduit par un arrêt dans la progression externe de ce champignon sur la tige et a été également constaté après pré-inoculation du VMT sur feuilles de tabac var. "Xanthi nc ». Par contre, aucune protection n'apparaît par inoculation préalable du VMT sur tabac "Samsun nn " ou par apport sur tige décapitée (var. "Xanthi nc ») d'un filtrat de culture de la souche pathogène.

L'apport sur tige décapitée de tabac d'une espèce de Phytophthora (souche ou filtrat de culture) non pathogène pour cette plante serait donc susceptible d'induire conjointement des nécroses foliaires à distance, l'apparition précoce de protéines $b$ et un certain degré de protection vis-à-vis du parasite ; par contre, l'espèce pathogène (souche ou filtrat de culture) n'induirait aucune de ces 3 réactions.

Mots clés additionnels : Filtrats de culture; incompatibilité ; électrophorèse. interactions.

On stems of detopped tobacco plants (cv. "Xanthi nc " or cv. "Samsun nn ", 50-65 days old) were placed either mycelial cultures or culture filtrates (20- $\mu \mathrm{l}$ drops) of different species of Phytophthora. Four days after inoculation or treatment, symptoms of foliar toxicity were noted and extractions performed from the upper leaves for the presence of b-proteins detected by polyacrylamide-gel - electrophoresis ; samples giving positive or doubtful responses were assayed by immuno-electrophoresis (against an anti-b-proteins serum from "Xanthi " inoculated with TMV) and amounts were determined by HPLC. Control detopped plants received drops of water or unused culture medium. TMV - inoculated plants, either cv. "Xanthi nc " (hypersensitive reaction and presence of b-proteins) or cv. «Samsun nn " (systemic infection and absence of b-proteins) also served as controls. With tobacco cv. "Xanthi nc " and six different non-compatible Phytophthora species (other than $P$. parasitica var. nicotianae $-P P N$ ), all strains and culture filtrates induced various levels of foliar toxicity and the presence of b-proteins ; under the same experimental conditions, four strains (and culture filtrates) of compatible $P P N$, and also control treatments with water or culture medium, induced no foliar necrosis and no b-proteins (table $1 \mathrm{~A}$ ). The b-proteins induced by non-compatible interactions seemed similar to the b-proteins coming from the HR reaction between TMV and cv. "Xanthi nc " : Rf in electrophoresis, serological reactions and retention time in HPLC were identical. A few assays were performed on tobacco cv. "Samsun nn " with two non-compatible strains (and filtrates) and four strairis (and filtrates) of pathogen with similar results (table 1B). When amounts of b-protein are detected $2,4,8$ and 15 days after inoculation, the non-compatible 
interaction showed a rapid increase of $b 1$ protein followed by a decrease whereas, with compatible interactions, b1 protein was slowly and weakly produced (fig. 3B); accordingly the difference between compatible and noncompatible interactions with respect to b-proteins seemed quantitative rather than qualitative as it appeared in early detection four days after inoculation. Furthermore when tobacco plants (cv. "Xanthi nc ") were preinoculated with different non-compatible strains (or treated with their culture filtrates) and then inoculated with $P P N$, invasion by the pathogen was partially inhibited (external necrosis was stopped) ; similar results were observed after $P P N$ inoculation of the stem of TMV - pre-inoculated tobacco plants cv. "Xanthi nc ». In contrast no resistance was observed when $P P N$ was inoculated onto TMV - pre-inoculated tobacco plants $\mathrm{cv}$. «Samsun nn " or on-to tobacco plants (cv. "Xanthi nc ") pre-treated with culture filtrates from PPN (fig. 4). Thus the treatment of tobacco stem with non-compatible species of Phytophthora (strains or culture filtrates) at one time induced foliar necrosis and b-proteins, and increased resistance to the compatible species $P$. parasitica var. nicotianae; under the same experimental conditions, these three reactions were not induced by strains or culture filtrates of the pathogen.

Additional key words : Culture filtrates; incompatibility ; electrophoresis.

\section{INTRODUCTION}

Dans les relations hôte-parasite entre tabac et divers microorganismes, différents phénomènes ont été décrits et abondamment étudiés. C'est le cas, tout d'abord, du phénomène d'hypersensibilité vis-à-vis du virus de la mosaïque du tabac (VMT). Inoculé sur les feuilles d'un tabac var. "Samsun nn», le virus devient systémique sans provoquer de lésion nécrotique au lieu d'inoculation (interaction compatible); l'inoculation à un tabac «Xanthi nc» aboutit à l'apparition de lésions nécrotiques d'hypersensibilité et à une localisation du virus aux points d'inoculation (interaction que nous appellerons non compatible). On a pu montrer par ailleurs que, dans le $2^{e}$ cas, il apparaissait de nouvelles protéines appelées "pathogenesis-related proteins" (ou P.R.S. : VAN LOON \& VAN KAMMEN, 1970) ou protéines b (GIANINAZZI et al., $1969 \& 1970)$ et que celles-ci étaient absentes dans l'interaction compatible. Les 2 types d'interaction sont donc définis par l'inoculation du même parasite (VMT) à 2 variétés distinctes de tabac et se caractérisent par l'absence (interaction compatible) ou la présence conjointe de lésions nécrotiques et de protéines $b$ (interaction incompatible).

Quant à l'état de résistance vis-à-vis d'un pathogène, il a été mis en évidence chez diverses plantes, soit en les pré-inoculant par un microorganisme vivant tel que virus (Ross, 1961) ou champignon compatible (KUĆ et al., 1975) ou incompatible (HAMMERSCHMIDT et al., 1976), soit en les prétraitant par des extraits de l'agent pathogène (ROSSIGNOL, 1979). Avec le tabac une protection vis-à-vis de Phytophthora parasitica (Dast.) var. nicotianae (B. de Haan) a été induite par une préinoculation du virus VMT sur tabac hypersensible (Mc INTYRE \& DODDS, 1979). Or, dans les interactions entre le tabac et le genre Phytophthora, on a déjà constaté (BONNET, 1985) que l'inoculation des diverses espèces de .Phytophthora incompatibles (différentes de l'espèce pathogène $P$. parasitica var. nicotianae) à des tiges décapitées de tabac se caractérise par un envahissement caulinaire faible ou nul et l'apparition de lésions nécrotiques foliaires à distance, dans les 2 à $3 \mathrm{j}$ suivant l'inoculation; avec certaines espèces $(P$. cryptogea Pethy \& Laff., $P$. cinnamomi Rands, $P$. megasperma Drechsl.) les nécroses foliaires sont très importantes; avec d'autres $[P$. parasitica Dast., $P$. cactorum (Lebert \& Cohn) Schroeter, $P$. citrophthora (Smith \& Smith) Leonian, P. capsici Leonian] elles sont de faible intensité pour $16 \mathrm{~h}$ d'éclairement, mais susceptibles de s'accentuer pour $8 \mathrm{~h}$ d'éclairement. En outre, les filtrats de culture de ces mêmes espèces provoquent nécroses et flétrissement quand ils sont appliqués à des feuilles détachées de tabac ou à de jeunes plants par voie racinaire. Par contre, les divers isolats de l'espèce pathogène $P$. parasitica var. nicotianae envahissent la tige inoculée sans apparition d'aucune lésion nécrotique foliaire, et les filtrats de culture n'entraînent ni nécrose, ni flétrissement sur feuilles détachées ou sur jeune plant.

L'interaction incompatible Phytophthora-tabac se différenciant donc déjà de l'interaction compatible par des lésions nécrotiques foliaires, nous avons voulu voir s'il était possible :

1) de détecter la présence de protéines b, après inoculation ou après apport de filtrat de culture,

2) de préciser la cinétique de ces protéines néoformées, si elles apparaissaient,

3) d'induire un certain degré de protection vis-à-vis des souches pathogènes de Phytophthora, soit par pré-inoculation du tabac avec des espèces incompatibles, soit après apport de divers filtrats de culture fongique et de comparer cet état de protection à celui induit par le VMT.

\section{MATÉRIEL ET MÉTHODES}

\section{A. Matériel biologique}

Les tabacs - cultivars "Xanthi ne » ou «Samsun $\mathrm{nn}$ " - sont élevés en serre puis placés en chambre climatisée $\left(23-24{ }^{\circ} \mathrm{C} ; 16 \mathrm{~h}\right.$ de lumière) 8 à $10 \mathrm{j}$ avant inoculation (plants âgés de 50 à $65 \mathrm{j}$ suivant les essais).

Sont utilisées 4 souches de $P$. parasitica var. nicotianae (NIC. 180, 181, 182 et 183) et 10 souches de Phytophthora représentant les principales espèces: $P$. cactorum (CAC. 195), P. parasitica (PAR. 26 et 44), P. capsici (CAP. 147), P. citrophthora (CIT 233), P. megasperma (MEG. 151), P. cinnamomi 
(CIN. 122), $P$. cryptogea (CRY. 52 et 192) et $P$. drechsleri (DRE. 165) ; les caractéristiques de ces souches et l'obtention de filtrats de culture sur milieu PliCH \& RUDNICKI (1979) ont déjà été décrites (BONNET, 1985)

\section{B. Système expérimental : inoculations, apport des filtrats de culture et symptômes}

Le plant de tabac est décapité laissant 4 à 5 feuilles bien développées. Pour les Phytophthora, on apporte au sommet de la tige soit une pastille de culture mycélienne (milieu gélosé à 1 p. 100 de malt) soit une goutte de $20 \mu \mathrm{l}$ de filtrat de culture non dilué et chaque traitement est effectué sur 2 plants. Quatre jours après, on mesure, dans le cas des inoculations mycéliennes, l'envahissement caulinaire, expression de l'agressivité des diverses espèces de Phytophthora sur la tige de tabac; on note également les symptômes de nécroses foliaires dont l'importance est exprimée par le nombre de feuilles ( 8 à 10 sur les 2 plants) présentant des zones nécrotiques couvrant moins $(\varepsilon /+)$ ou plus $(++)$ du quart de la surface foliaire. On prélève alors, sur les 2 plants de chaque traitement, les feuilles $n^{\circ} 2,3$ et 4 à partir de l'apex décapité (fig. 1).

Pour le virus de la mosaique du tabac (VMT), on inocule le virus (souche commune à $25 \mu \mathrm{g} / \mathrm{ml}$ ) par frottis sur les feuilles $n^{\circ} 2,3$ et 4 à partir de l'apex et ces feuilles sont prélevées $4 \mathrm{j}$ après inoculation pour extraction des protéines $b$.

Dans l'essai concernant la cinétique d'apparition de la protéine b1, 3 lots de tabac var. "Xanthi nc » ont été inoculés comme précédemment par 2 souches de $P$. parasitica var. nicotianae choisies pour leurs différences d'agressivité (forte pour NIC. 183, moyenne pour NIC. 182) et par une souche de Phytophthora non compatible (PAR. 26) choisie pour son voisinage

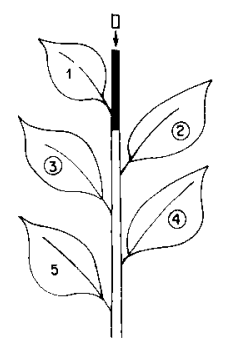

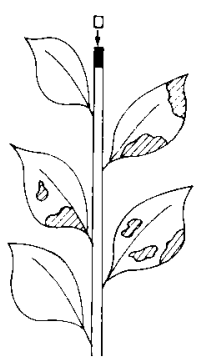

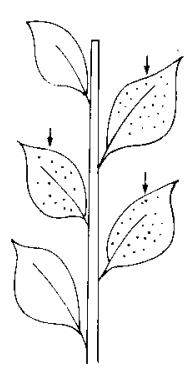

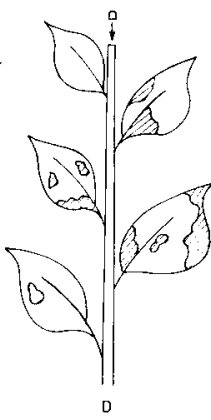

Figure 1

Schémas de 4 types d'interactions (4e jour - tabac Xanthi). Inoculations mycéliennes $(\square)$, souche compatible $(A)$ ou incompatible (B).

Filtrat de culture (O) en (D) et inoculation VMT (C)

Envahissement caulinaire ( $\mathbf{D})$, nécroses d'hypersensibilité virale (目) et nécroses foliaires fongiques (囚). Feuilles prélevées pour protéines $b$ :(2) (3) (4).

Schemes of different interactions on tobacco plants : mycelial inoculation ( $\square)$, with compatible $(A)$ or non compatible strains $(B)$ drop of culture filtrate or T.M.V. inoculation $(D$ and $C$ respectively).

Stem necrosis ( $\square$ ), hypersensitive reaction with T.M.V. (ख) and necrotic areas on leaves with fungus (๒). Leaves extracted for $b$ proteins : (2) (3) (4). taxinomique avec les précédentes et son agressivité assez proche de celle de la souche NIC. 182. L'envahissement caulinaire étant différent d'une souche à l'autre on prélève, sur chaque lot de 2 plants $(2,4,8$ et $15 \mathrm{j}$ après inoculation) les 2 feuilles situées immédiatement sous la zone caulinaire envahie.

Enfin, à chacune des dates de prélèvement on a pris, sur un $4^{\mathrm{e}}$ lot de plants témoins (décapités et non inoculés), les feuilles des étages correspondants à ceux des plants inoculés.

\section{Extraction, mise en évidence et dosage des protéi- nes b}

L'extraction de chaque lot de feuilles prélevées se fait par broyat au mortier, à raison de $1 \mathrm{ml} / \mathrm{g}$ de feuilles, en tampon $\mathrm{A}$ à $\mathrm{pH} 2,8$ (acide citrique : $84 \mathrm{mM}$; $\mathrm{Na}_{2} \mathrm{HPO}_{4}$ : $32 \mathrm{mM} ; 2$ mercapto-éthanol : $14 \mathrm{mM}$; L-acide ascorbique : $6 \mathrm{mM}$ ) (ANTONIW \& PIERPOINT, $1978)$; après filtration sur mousseline et 2 centrifugations (5000 g $10 \mathrm{mn}$ et $20000 \mathrm{~g} 15 \mathrm{mn}$ ), le surnageant est précipité par 50 p. 100 (poids/vol.) de sulfate d'ammonium durant $30 \mathrm{mn}$ à $4{ }^{\circ} \mathrm{C}$; le culot obtenu après centrifugation de $20 \mathrm{mn}$ à $10000 \mathrm{~g}$ est repris dans $0,2 \mathrm{ml} / \mathrm{g}$. MF en tampon Tris- $\mathrm{HCl} \mathrm{pH} 8$ (GIANINAZZl et al., 1977 ; ANTONIW et al., 1980 ; ABAD et al., 1985). Des extraits ainsi obtenus, $50 \mu \mathrm{l}$ sont soumis à une électrophorèse sur gel de polyacrylamide à 15 p. 100 (tampon Tris-glycine pH 8,3 et environ $3 \mathrm{~h} 30$ à 100 volts constants et $4{ }^{\circ} \mathrm{C}$ ) ; les gels sont colorés au bleu de Coomassie.

Dans chaque série d'échantillons, on inclut un extrait tabac «Xanthi nc »-VMT comme témoin positif de bande protéinique bl. Les échantillons ayant donné une réponse positive (ou douteuse) au niveau de la bande bl sont soumis à une immunoélectrophorèse : électrophorèse sur lame pendant $150 \mathrm{mn}$ à $240 \mathrm{~V}$ en tampon véronal suivie d'une immuno-précipitation avec sérum anti-protéines b (DEverGNe \& CARDIN, 1967) ; dans chaque série de lames, un témoin positif est inclus sous forme d'antigène protéines $b$ partiellement purifié (isolement de «Xanthi nc » inoculé par VMT et purification sur D.E.A.E. cellulose) (ABAD et al., 1985). Enfin les réponses qualitativement positives avec les 2 techniques précédentes sont dosées en système H.P.L.C. (ABAD et al., 1985).

\section{Essais d'induction de résistance vis-à-vis du patho- gène}

Trois types d'inducteurs ont été comparés : cultures mycéliennes (Phytophthora non compatibles), filtrats de culture (Phytophthora compatibles et non compatibles), virus de la mosaïque du tabac (VMT).

Avec les Phytophthora (fig. 4A), souches (S) et filtrats de culture (F) ont été apportés sur tige décapitée comme précédemment (cf. § II, B) et on a pris comme témoins des plants prétraités soit avec de l'eau ( $\mathrm{T} \mathrm{H}_{2} \mathrm{O}$ ) soit avec du milieu de culture non ensemencé (T M). Les divers prétraitements entraînent, selon les cas, l'apparition de symptômes nécrotiques foliaires d'intensités variables et notés par un chiffre ( 0 à 5) indiquant le nombre de feuilles présentant des nécro- 
ses. Par ailleurs l'induction par pré-inoculation des souches de Phytophtora incompatibles entraînant un certain envahissement de la tige, il a fallu recouper celleci (sous la lésion nécrotique visible) avant de surinoculer le Phytophthora pathogène ; pour comparer au mieux les 2 systèmes d'induction, les tiges prétraitées par filtrats ont été également recoupées sur $2 \mathrm{~mm}$ environ avant la surinoculation. Celle-ci a été réalisée dans tous les cas avec la souche NIC. 183 et $2 j$ après l'apport des différents inducteurs.

Dans le cas du virus (fig. 4B), 2 feuilles de chaque plant ont été traitées soit par du VMT (lésions d'hypersensibilité avec le tabac « Xanthi nc ») soit par de l'eau $(\mathrm{T}) ; 7 \mathrm{j}$ après, les plants sont décapités et inoculés par le Phytophthora pathogène (NIC. 181).

On suit alors l'invasion du parasite par des mesures échelonnées $(4,8,12 \mathrm{j})$ de la nécrose caulinaire externe ; la protection induite par les divers traitements apparaît donc comme un ralentissement, voire un blocage, de la nécrose externe comparée à celle de témoins non traités. En fin d'expérience, les tiges sont coupées longitudinalement pour noter l'invasion interne.

\section{RÉSULTATS OBTENUS}

\section{A. Symptômes et protéines b avec le tabac var. "Xanthi ne » (tabl. lA).}

En ce qui concerne les inoculations (tabl. lA, en haut), il faut d'abord remarquer que, conformément à des résultats précédents (BONNET, 1985), les 4 souches du pathogène envahissent la tige sans provoquer de nécroses foliaires; par contre, les 8 souches incompatibles donnent des envahissements caulinaires limités mais des toxicités foliaires variables suivant l'espèce inoculée : faibles avec les 3 espèces peu nécrosantes ( $P$. cactorum, $P$. parasitica et $P$. capsici), elles s'accusent nettement (feuilles à nécroses ++ ) avec les 3 autres espèces $P$. megasperma, $P$. cinnamomi et P. cryptogea.

Quant aux filtrats de culture (tabl. 1A, bas), le dépôt de $20 \mu \mathrm{l}$ au sommet de tiges décapitées entraîne des symptômes de nécroses foliaires parallèles à ceux des inoculations.

Après $4 \mathrm{j}$, l'envahissement caulinaire des souches les plus pathogènes (NIC. 181 et NIC. 183) dépasse le niveau de la $1^{\text {re }}$ feuille (envahissement de la base du pétiole, flétrissement de la feuille) mais n'atteint pas encore le pétiole de la feuille $\mathrm{n}^{\circ} 2$. Dans ces conditions, la recherche de protéines $b$ dans les feuilles $\mathrm{n}^{\circ} 2,3$ et 4 (cf. fig. 1) montre que, qualitativement :

- Elles sont présentes dans les 8 cas d'inoculation par des souches non compatibles alors qu'elles sont absentes après inoculation des différentes souches compatibles du pathogène.

- L'apport de filtrats de culture sur tige décapitée aboutit à des résultats parallèles à ceux des inoculations : présence de protéines $b$ uniquement avec les filtrats des souches non compatibles.

- Les protéines b produites par les Phytophthora non compatibles (souches ou filtrats) sont identiques à celles induites par le VMT chez le tabac « Xanthi

TABLEAU 1A

Inoculations de Phytophthora compatibles (P. PAR. var. NIC.) et incompatibles ou apport des filtrats de culture correspondants (20 $\mu l$ ) sur tiges décapitées de tabac var. "Xanthi nc ». Résultats 4 jours après traitement; chaque colonne représente un essai :

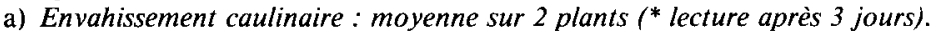

b) Sur 8 à 10 feuilles bien développées pour les 2 plants, nombre de feuilles à zones nécrotiques couvrant moins $(\varepsilon)+1$ ou plus $(++)$ du quart de la feuille. Pour le VMT nombre de feuilles inoculées avec nécroses (**).

c) Mise en évidence de la protéine bl par électrophorèse (P.A.G.E.), immunoélectrophorèse (I.E.) el H.P.L.C. (Mg protéines bI/gMF).

Results obtained 4 days after inoculations on detopped tobacco stems ("Xanthi nc 》) with non compatible or compatible (P. PAR. var. NIC.) strains of Phytophthora or with different culture filtrates.

a) Average length (2 plants) of stem necrosis (*after 3 days).

b) Total leaves with necrotic areas less $(\varepsilon /+)$ or larger than a quarter of the leaf $(8$ to 10 leaves on 2 inoculated plants). Number of leaves with necrotic lesions after T.M.V. inoculations (**).

c) Presence of bl protein in electrophoresis (P.A.G.E.), immunoelectrophoresis (I.E.) and H.P.L.C. ( $\mu$ g of bI protein/g fresh weight).

\begin{tabular}{|c|c|c|c|c|c|c|c|c|c|c|c|c|c|c|c|c|c|c|c|c|c|c|c|c|c|}
\hline \multirow{2}{*}{\multicolumn{3}{|c|}{$\frac{\text { Phytophthora : espèces }}{\text { Isolats }}$}} & \multicolumn{8}{|c|}{ PAR var. NIC. } & $\mathrm{CAC}$. & \multirow{2}{*}{\multicolumn{3}{|c|}{$\frac{\text { PAR. }}{26}$}} & \multirow{3}{*}{\begin{tabular}{l|l} 
& \\
44 & \\
4 &
\end{tabular}} & \multirow{3}{*}{\begin{tabular}{|l|} 
CAP \\
147 \\
18 \\
\end{tabular}} & \multirow{3}{*}{\begin{tabular}{|c|} 
MEG. \\
151 \\
2 \\
\end{tabular}} & \multirow{3}{*}{\begin{tabular}{|c|} 
CIN. \\
122 \\
15 \\
\end{tabular}} & \multicolumn{3}{|c|}{ CRY. } & \multirow{2}{*}{\multicolumn{4}{|c|}{ V.M.T. }} \\
\hline & & & 180 & & 181 & & 182 & & 183 & & 195 & & & & & & & & \multirow{2}{*}{\multicolumn{2}{|c|}{$\frac{52}{12}$}} & \multirow{2}{*}{$\frac{192}{9}$} & & & & \\
\hline $\begin{array}{l}\mathrm{I} \\
\mathrm{N} \\
\mathrm{O}\end{array}$ & $\begin{array}{l}\text { Tige (mm) } \\
\text { (a) }\end{array}$ & & 3 & $\begin{array}{l}34 \\
(*)\end{array}$ & $\begin{array}{l}32 \\
\left(^{*}\right)\end{array}$ & 51 & $11 \quad 18$ & $\begin{array}{l}32 \\
(*)\end{array}$ & 56 & 44 & 2 & 25 & 21 & 18 & & & & & & & & & & & \\
\hline $\begin{array}{l}C \\
U \\
\text { L } \\
\text { A }\end{array}$ & $\begin{array}{l}\text { Nécroses } \\
\text { feuilles } \\
\text { (b) }\end{array}$ & $\begin{array}{l}t /+ \\
++\end{array}$ & $\begin{array}{l}0 \\
0\end{array}$ & $\begin{array}{l}0 \\
0\end{array}$ & $\begin{array}{l}0 \\
0\end{array}$ & $\hat{0}$ & $\begin{array}{ll}0 & 0 \\
0 & 0\end{array}$ & $\begin{array}{l}0 \\
0\end{array}$ & $\begin{array}{l}0 \\
0\end{array}$ & $\begin{array}{l}0 \\
0\end{array}$ & $\begin{array}{l}0 \\
0\end{array}$ & $\begin{array}{l}0 \\
0\end{array}$ & $\begin{array}{l}0 \\
0\end{array}$ & $\begin{array}{l}1 \\
0\end{array}$ & $\begin{array}{l}2 \\
0\end{array}$ & 2 & $\begin{array}{l}8 \\
0\end{array}$ & 5 & $\begin{array}{l}0 \\
7\end{array}$ & & $\begin{array}{l}8 \\
2\end{array}$ & 3 & 3 & ${ }^{3}{ }^{3}$ & 3 \\
\hline $\begin{array}{l}\mathrm{T} \\
1 \\
0 \\
\mathrm{~N} \\
\mathrm{~S}\end{array}$ & $\begin{array}{l}\text { Protéine } b^{1} \\
\text { (c) }\end{array}$ & $\begin{array}{l}\text { P.A.G.E. } \\
\text { I.E. } \\
\text { H.P.L.C. }\end{array}$ & $\begin{array}{l}0 \\
0 \\
0\end{array}$ & $\begin{array}{l}0 \\
0\end{array}$ & $\begin{array}{l}0 \\
0\end{array}$ & $\begin{array}{l}0 \\
0 \\
0\end{array}$ & $\begin{array}{cc}0 & ? \\
0 & \\
& 0.13\end{array}$ & $\begin{array}{l}0 \\
0\end{array}$ & $\begin{array}{l}0 \\
0\end{array}$ & 0 & $\begin{array}{l}+ \\
+ \\
1.0\end{array}$ & $\begin{array}{l}+ \\
+ \\
1,9\end{array}$ & $\begin{array}{l}+ \\
+ \\
3,7\end{array}$ & $\begin{array}{l}+ \\
+ \\
7,3\end{array}$ & $\begin{array}{c}+ \\
+ \\
4.6\end{array}$ & $\begin{array}{c}+ \\
1 \\
10,8\end{array}$ & $\begin{array}{l}+ \\
+ \\
9.7\end{array}$ & + & $\begin{array}{l}+ \\
+ \\
4\end{array}$ & & $\begin{array}{c}+ \\
+ \\
15.4\end{array}$ & $\begin{array}{l}+ \\
+ \\
14.4\end{array}$ & $\begin{array}{l}+ \\
+ \\
10,8\end{array}$ & $\begin{array}{l}+ \\
+ \\
23.8\end{array}$ & $\begin{array}{l}+ \\
+ \\
9,7\end{array}$ \\
\hline $\begin{array}{ll}\text { F } & \text { C } \\
\text { I } & U \\
\text { L } & \text { L } \\
\text { T } & \text { T } \\
\text { R } & U\end{array}$ & $\begin{array}{l}\text { Nécroses } \\
\text { feuiltes } \\
- \text { (b) }\end{array}$ & $\begin{array}{l}t+ \\
t+\end{array}$ & $\begin{array}{l}0 \\
0\end{array}$ & $\begin{array}{l}0 \\
0\end{array}$ & & $\begin{array}{l}0 \\
0\end{array}$ & $\begin{array}{l}0 \\
0\end{array}$ & $\begin{array}{l}0 \\
0\end{array}$ & & $\begin{array}{l}0 \\
0\end{array}$ & $\begin{array}{l}0 \\
0\end{array}$ & & $\begin{array}{l}2 \\
0\end{array}$ & & $\begin{array}{l}1 \\
0\end{array}$ & 3. & 5 & $\begin{array}{l}1 \\
x\end{array}$ & $\begin{array}{l}7 \\
1\end{array}$ & $\begin{array}{l}1 \\
7\end{array}$ & $\begin{array}{l}1 \\
9\end{array}$ & & & & \\
\hline $\begin{array}{ll} & K \\
T & E \\
S & \\
(20 & \mu l)\end{array}$ & $\begin{array}{l}\text { Protéine } b^{1} \\
\text { (c) }\end{array}$ & $\begin{array}{l}\text { P.A.G.E. } \\
\text { I.E. } \\
\text { H.P.L.C. }\end{array}$ & $\begin{array}{l}0 \\
0\end{array}$ & $?$ & & $\begin{array}{l}0 \\
0\end{array}$ & 0 & $\begin{array}{l}? \\
0\end{array}$ & & $\begin{array}{l}0 \\
0 \\
0\end{array}$ & $\begin{array}{l}+ \\
+ \\
14,8\end{array}$ & & $\begin{array}{l}+ \\
+ \\
12,6\end{array}$ & + & $\mid \begin{array}{l}+ \\
+ \\
+ \\
\text { NT }\end{array}$ & $\begin{array}{c}+ \\
+ \\
+ \\
41,8\end{array}$ & $\begin{array}{c}+ \\
+ \\
+ \\
25.3\end{array}$ & $\begin{array}{l}+ \\
+ \\
6,9\end{array}$ & $\begin{array}{l}+ \\
+ \\
13,8\end{array}$ & $\begin{array}{l}+ \\
+ \\
18,9\end{array}$ & $\begin{array}{c}1 \\
+ \\
11,7\end{array}$ & & & & \\
\hline
\end{tabular}


nc »; en effet, des extraits du couple VMT-tabac "Xanthi nc » ont servi de références permanentes au cours des différents essais et ont permis de constater une identité entre les protéines bl produites dans les 2 systèmes : identité des $\mathbf{R} f$ en électrophorèse, parenté sérologique en immuno-électrophorèse (fig. 2B), même temps de rétention en H.P.L.C.

D'un point de vue quantitatif les résultats des dosages en H.P.L.C. de la protéine b1 doivent être considérés avec prudence : de nombreux cas de figure n'ont en effet été testés qu'une seule fois; or la variabilité des chiffres obtenus au cours de différents essais avec une même souche est manifeste (cf. par exemple inoculation de la souche 26 ). Ces résultats, bien que rela-

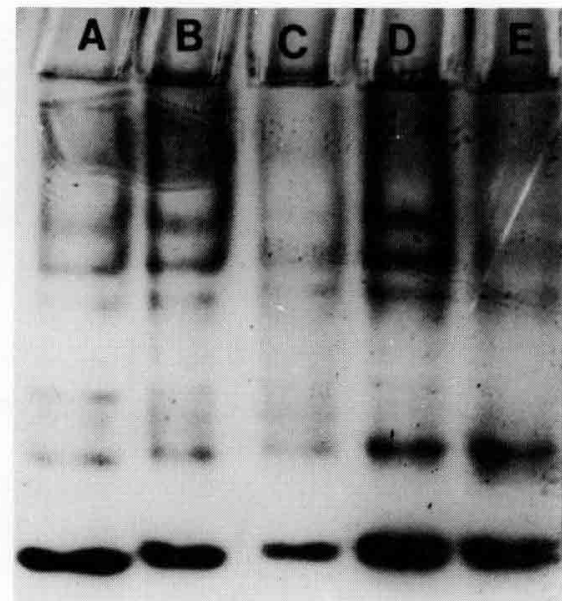

2B

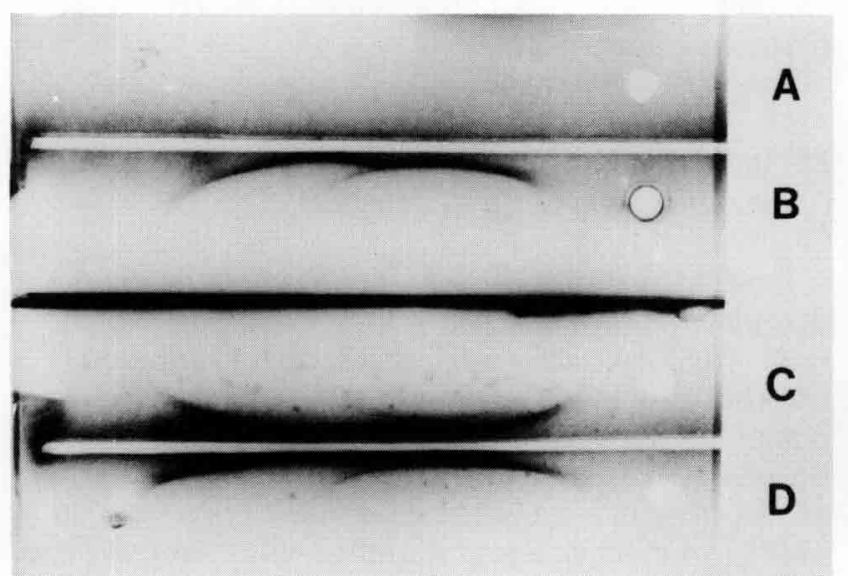

Figure 2

2A. - Gel d'électrophorèse: Tabac "Xanthi nc" 4 jours après inoculation par VMT (A), P. cryptogea $N^{\circ} 52(C)$ et $N^{\circ} 192(D)$ ou apport de filtrat de culture $(20 \mu l)$ de $\mathrm{P}$. cryptogea $N^{\circ} 52(B)$. Tabac "Samsun nn " après inoculation par P. parasitica $N^{\circ} 26(E)$.

2B. - Lames d'immuno-électrophorèse. Tabac «Xanthi nc» : inoculation par VMT (B) ou apport de filtrat de culture $(20 \mu l)$ de NIC. 183 (A) ou de CRY. 52 (C). Tabac "Samsun nn » après apport de filtrat de culture de CRY. 52 (D).

2A. - Electrophoresis of leaf extracts from "Xanthi nc " either inoculated with T.M.V., P. cryptogea $N^{\circ} 52$ and $N^{\circ} 192(A, C$ and $D$ respectively) or having received on stem $20 \mu l$ of culture filtrate from $\mathrm{P}$. cryptogea $N^{\circ} 52(B)$. Leaf extract from «Samsun nn » inoculated with $\mathrm{P}$. parasitica $N^{\circ} 26(E)$.

2B. - Immunoelectrophoresis reactions : inoculation with T.M.V. (B) or drop of culture filtrate from NIC. $183($ A) on "Xanthi nc"; culture filtrate from CRY. 52 on "Xanthi nc" (C) or "Samsun $n n$ » $(D)$. tifs, permettent toutefois de faire 3 constatations : tout d'abord l'induction des protéines b par un filtrat de culture semble généralement supérieure comparée à l'induction par la souche homologue incompatible. Ensuite les interactions incompatibles peu nécrosantes au niveau foliaire induisent des quantités de protéines b au moins aussi fortes que les interactions fortement nécrosantes et ce aussi bien avec les souches (PAR. 44 et CRY. 52) qu'avec les filtrats (CAC. 195 et CRY. 52). Enfin l'inoculation par le VMT fait apparaître un taux de protéines b généralement supérieur à celui obtenu par inoculation des souches de Phytophthora incompatibles mais voisin de celui obtenu par apport de filtrats.

\section{B. Symptômes et protéines b sur tabac var. "Sam- sun nn » (tabl. 1B)}

Les résultats obtenus sur «Samsun nn » (tabl. 1B) sont très voisins de ceux obtenus avec le «Xanthi nc » : présence de protéines b avec les 2 Phytophthora incompatibles essayés (PAR. 26 et CRY. 52), absence avec les 4 souches de l'espèce pathogène et après inoculation par le VMT. On peut toutefois remarquer qu'avec les souches pathogènes les réponses de protéines b sont négatives ou très faibles après inoculation mais qu'elles deviennent faiblement positives dans certains cas après apport de filtrat de culture (F. 181). Sur "Samsun nn " donc, les réponses différentielles entre souches pathogènes et souches incompatibles ne semblent plus aussi tranchées que celles obtenues avec la var. «Xanthi nc »; se posait dès lors le problème de savoir si la différence d'induction de protéines b entre Phytophthora pathogène et Phytophthora incompatible était d'ordre qualitatif ou quantitatif ; d'où la mise en place d'un essai de cinétique d'apparition de ces protéines.

Il faut noter enfin qu'on n'a pu mettre en évidence de protéines b dans aucun des plants témoins envisagés : plants non décapités ou plants décapités avec apport de $20 \mu \mathrm{l}$ d'eau ou de milieu de culture sur le sommet de la tige, et ce aussi bien avec la variété "Xanthi nc » qu'avec la variété "Samsun nn ».

\section{Cinétiques comparatives d'apparition de la protéine $b_{1}$ induite par 3 souches de Phytophthora chez var. « Xanthi nc "}

Les résultats montrent (fig. 3A) que la souche pathogène NIC. 183 envahit très rapidement la tige inoculée durant les 8 premiers jours ; l'évolution de l'autre souche pathogène, NIC. 182, est notablement plus réduite; avec la souche PAR. 26 on assiste à un envahissement $\mathrm{du} 1^{\mathrm{er}}$ entre-nœud de la tige inoculée suivi d'un arrêt vers le $4^{\mathrm{e}} \mathrm{j}$. Des nécroses foliaires apparaissent dès le $2^{\mathrm{e}} \mathrm{j}$ avec la souche PAR. 26 et n'évoluent pratiquement plus après le $4^{\mathrm{e}} \mathrm{j}$; aucune nécrose foliaire n'est apparue, même après $15 \mathrm{j}$, avec les 2 souches du parasite. En ce qui concerne la production de protéines $b_{1}$, on peut constater (fig. 3B) que, dans la phase précoce après infection, elle n'apparaît pràtiquement pas avec les souches pathogènes NIC. 182 et 183 alors qu'elle est très nettement et 
TABLEAU IB

Resultats obtenus sur tabac var. «Samsun nn ». Inoculations, notations et légendes identiques au tableau IA. Results obtained on tobacco cv. "Samsun nn》 with conditions and notations as in table IA.

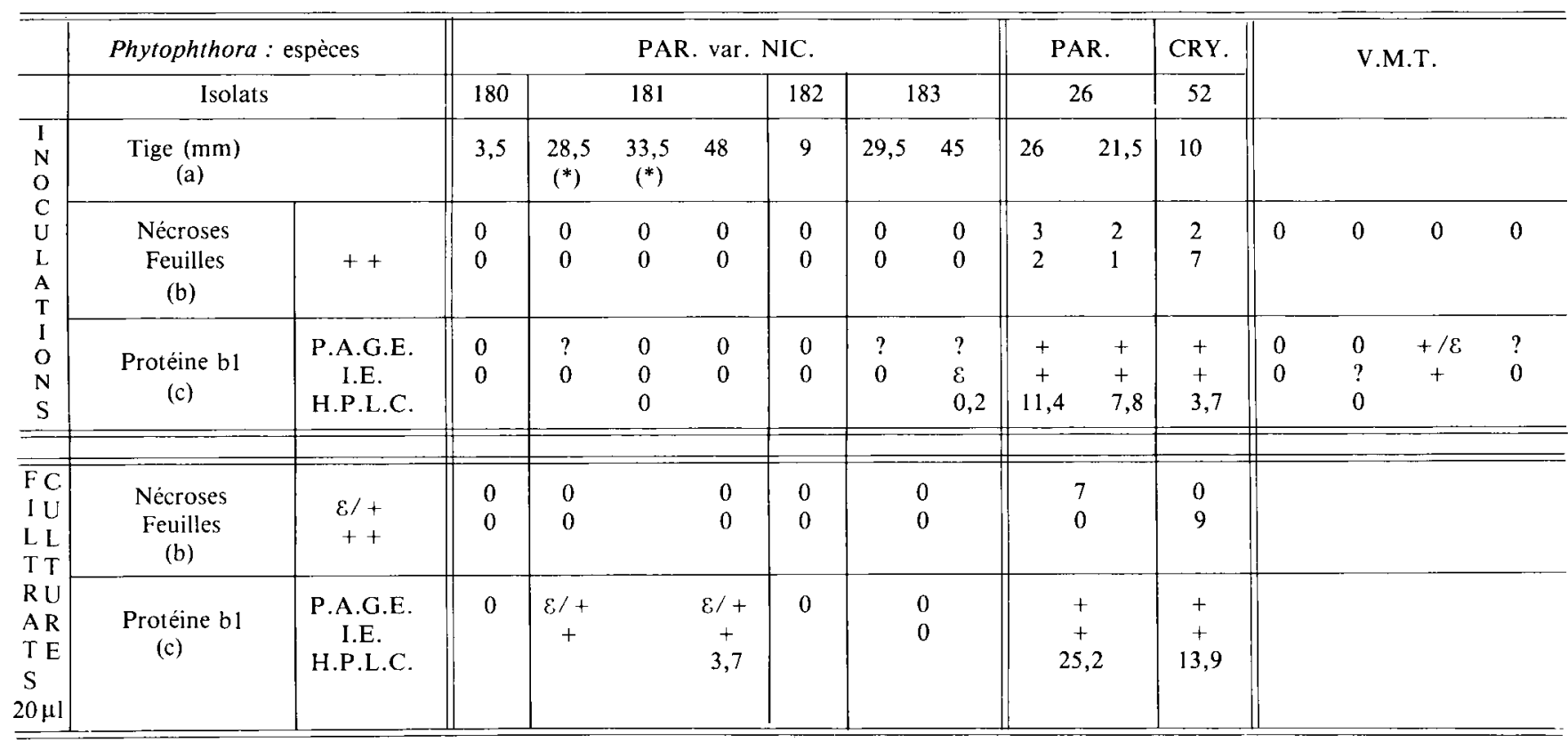
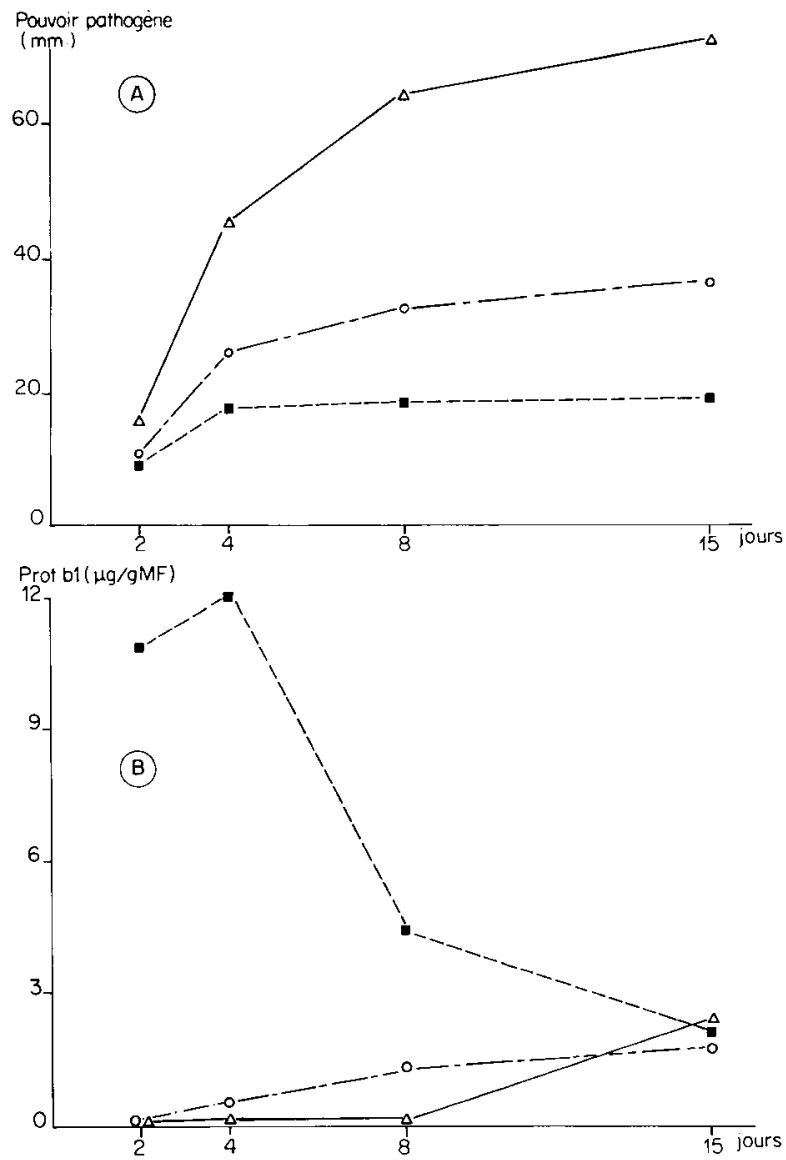

Figure 3

Cinétiques comparées du pouvoir pathogène (envahissement caulinaire : fig. 3A) et de l'accumulation des protéines bl (fig. 3B) après Inoculation de tabac var. "Xanthi nc » par 3 souches de Phytophthora : $\mathrm{P}$. parasitica var. nicotianae $183(\triangle), 183$ (O) et $\mathrm{P}$. parasitica 26 ( $\square)$.

Comparative progress of pathogenesis (stem necrosis fig. $3 \mathrm{~A}$ ) and amount of bl-proteins (fig. 3B) after inoculation of tobacco ( $X$ Xanthi nc ") with 3 strains of Phytophthora : P. parasitica var. nicotianae $183(\triangle)$ and $182(0)$, and $\mathrm{P}$. parasitica $26(\square)$. fortement induite par la souche incompatible PAR. 26, et ce dès le $2^{\mathrm{e}} \mathrm{j}$ après inoculation. Dans la phase tardive on assiste par contre à une diminution rapide du taux de protéine $b_{1}$ dans la combinaison incompatible, rejoignant - au $15^{\mathrm{e}} \mathrm{j}-$ le taux faible mais positif des 2 combinaisons compatibles. Enfin la recherche de protéines $b_{1}$ dans les feuilles de tabacs témoins, décapités et non inoculés, s'est révélée négative même après $15 \mathrm{j}$.

\section{Induction de résistance vis-à-vis de $P$. parasitica var. nicotianae}

Les inoculations du Phytophthora pathogène sur des plants prétraités par divers Phytophthora montrent (fig. 4A) une différence dans l'évolution des nécroses caulinaires externes entre plants prétraités et plants témoins. En effet, chez ces derniers, l'invasion du pathogène est relativement constante : elle atteint $40 \mathrm{mn}$ environ après $4 \mathrm{j}$ et continue à progresser du $4^{\mathrm{e}}$ au $8^{\mathrm{e}} \mathrm{j}$. Le schéma est sensiblement voisin avec les plants prétraités par les filtrats des souches compatibles (NIC. 181 et NIC. 183). Avec les plants prétraités par les souches (S) ou filtrats (F) incompatibles, on peut fréquemment observer la superposition de 2 phénomènes : une invasion du pathogène plus ou moins freinée dans la phase précoce $(0-4 \mathrm{j})$ puis totalement stoppée dans la phase tardive $(4-8 \mathrm{j})$. Les plants de tabac prétraités semblent donc avoir acquis un certain état de protection vis-à-vis du pathogène. Ce phénomène de protection induite apparaît également chez des plants de «Xanthi nc » pré-inoculés par le VMT $7 \mathrm{j}$ auparavant mais non chez les plants var. «Samsun nn " traités de façon identique (fig. 4B).

Toutefois, dans ces essais de prétraitement, 2 réserves sont à faire. D'abord certaines réactions de résistance sont irrégulières suivant les essais (cf. par exemple la variabilité des résultats avec F. 122), surtout 
(A) Prétraitements por divers Phytophthora, souches (S) ou filtrats (F)
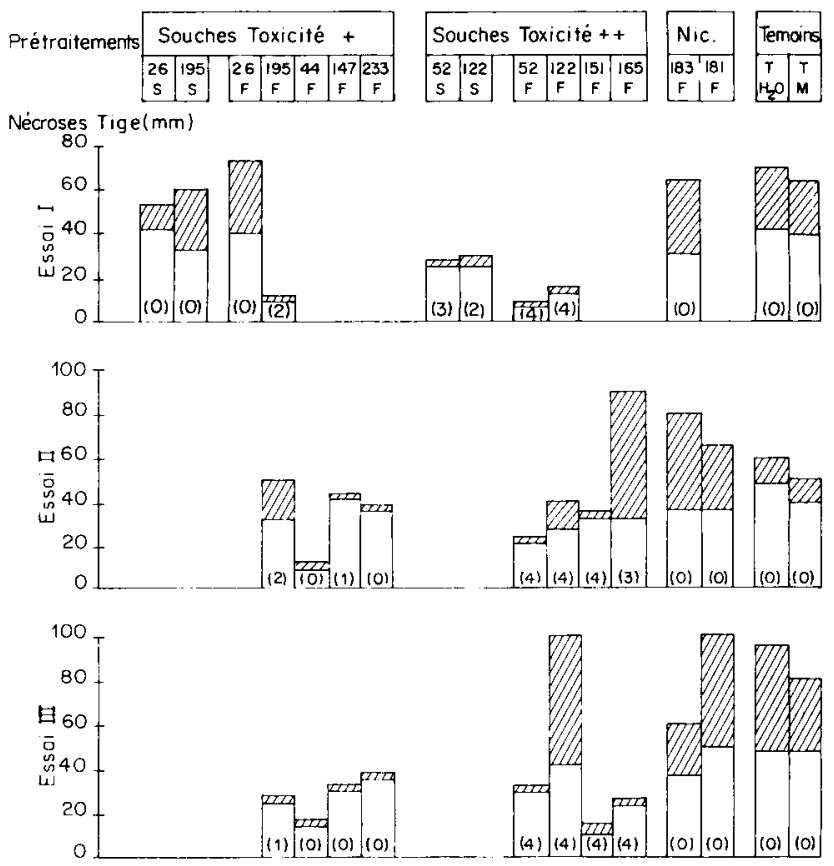

B) Prétraitement por V M.T

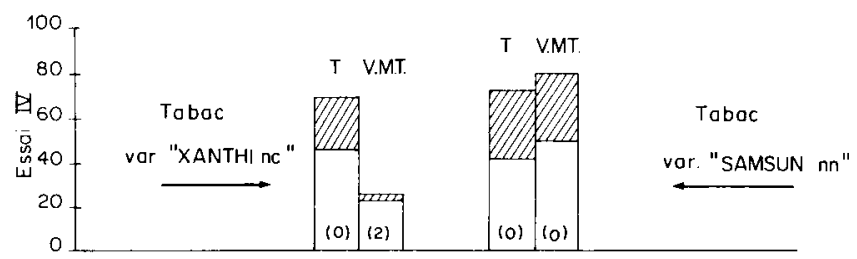

Figure 4

Induction de résistance vis-à-vis du $\mathrm{P}$. parasitica var. nicotianae par divers pré-traitements : envahissement caulinaire $4([7)$ et 8 jours () après inoculation du pathogène.

- A) Pré-traitement des plants par souches (S) ou filtrat de culture (F) à toxicité foliaire nulle (NIC.) faible $(+)$ ou forte $(++)$; tabac var. "Xanthi nc" âgés de 67, 76 et 90 jours (Essais I, II, III).

- B) Pré-traitement de tabac var. "Xanthi nc" ou «Samsun nn » aggés de 67 jours par frottis foliaire de VMT ou d'eau $(T), 7$ jours avant inoculation par NIC. 181 .

Protection against $\mathrm{P}$. parasitica var, nicotianae induced on tobacco plants by different treatments : stem necrosis 4 ( $\square$ ) and 8 days ( $\mathbb{Z}$ ) after inoculation with pathogen strain.

- A) Pre-treatment with strains (S) or culture filtrates (F) having no (NIC.). slight $(+)$ or strong $(++)$ foliar necrotic effects ; Tobacco «Xanthi nc " 67, 76 or 90 days old (Essavs I, II, III).

- B) Pre-treatment of tobacco ( Xanthi nc" or "Samsun nn" 67 days old) by pre-inoculation with T.M.V., 7 days before inoculation with NIC. 181 .

avec les pré-inoculations fortement toxiques (F. 122 et F. 165). Ensuite l'état de résistance observé ici n'est que partiel ; en effet, la pré-inoculation n'interdit pas, d'une part, la pénétration du pathogène lors de sa surinoculation (envahissement caulinaire entre 0 et 4 j) ; d'autre part, la surinoculation n'a entraîné un blocage de la progression du parasite que dans la partie externe de la tige mais non dans la partie médullaire : 8 ou $12 \mathrm{j}$ après l'inoculation du Phytophthora pathogène, les plants prétraités présentaient un envahissement caulinaire externe limité et un aspect extérieur parfaitement « sain » mais l'ouverture longidutinale des tiges en fin d'expérience a montré une invasion des tissus médullaires comparable à celle des témoins. Ces diverses remarques amènent donc à considérer ces résultats comme préliminaires et devant être précisés ultérieurement par une étude plus approfondie de certaines interactions.

\section{DISCUSSION ET CONCLUSIONS}

Par rapport aux résultats précédemment acquis (BONNET, 1985), ceux présentés ici apportent 3 points complémentaires :

- le dépôt de filtrats de culture d'espèces non compatibles sur tige décapitée de tabac (technique strictement parallèle donc à l'inoculation mycélienne) entraîne des réactions toxiques foliaires à distance comparables à celles obtenues par inoculation,

- l'inoculation ou l'apport de filtrats de culture d'espèces non compatibles sur tiges décapitées de tabac var. "Xanthi nc " et var. "Samsun nn » induit, $4 \mathrm{j}$ après, l'apparition de protéines $\mathrm{b}$ au niveau foliaire ; celles-ci n'apparaissent pas, dans ces conditions, avec les diverses souches de l'espèce pathogène,

- le prétraitement d'un plant de tabac var. "Xanthi nc ", soit par inoculation, soit par apport de filtrat de culture d'une espèce non compatible, semble induire un certain état de protection vis-à-vis d'une inoculation postérieure par la souche pathogène.

Il paraît intéressant de discuter divers aspects de ces résultats.

\section{A. Rapports entre nécroses foliaires et production de protéines b}

Les résultats obtenus sur «Xanthi nc » et concernant l'aspect nécrosant au niveau foliaire des espèces non compatibles rejoignent ceux précédemment décrits pour $16 \mathrm{~h}$ d'éclairement (BONNET, 1985); comparés aux inoculations, les filtrats donnent des résultats parallèles (tabl. 1A). Globalement donc, les espèces non compatibles apparaissent comme inductrices de nécroses foliaires; certaines, toutefois, en induisent peu (PAR. 26), voire aucune (CAC. 195) et ne se différencient dès lors plus, sous ces conditions d'éclairement, de l'espèce pathogène non nécrosante. La présence qualitative de protéines b chez toutes les interactions incompatibles (même les moins nécrosantes) permet donc de les différencier nettement de l'interaction compatible.

D'un point de vue quantitatif, des souches peu nécrosantes peuvent induire plus de protéines $b$ que des souches fortement nécrosantes $(10,8$ avec $P$. capsici et 4,8 par $P$. cryptogea) ; cette absence de corrélation entre intensité de nécroses et quantité de protéines $b$ pourrait se rapprocher d'observations faites par AHL (1981, 1983). Pourtant, dans certains cas, « la synthèse de protéines b paraît liée à la taille et à la densité des lésions locales nécrotiques » (GIANINAZZI et al., 1980), ce qui semblerait montrer que la relation entre nécroses et protéines b n'est pas encore très clairement établie et que la notion de «nécrose » n'est peut-être pas totalement identique suivant les modèles biologiques. 
On peut noter enfin que les plants témoins non inoculés, mais pourtant décapités, n'ont donné aucune production de protéines $\mathrm{b}$ même après $15 \mathrm{j}$ (cf. III, B et III, C).

\section{B. Protéines b chez les interactions hypersensibles et non compatibles}

La production rapide de proténes $\mathbf{b}$ chez le tabac après inoculation des Phytophthora non pathogènes (ou apport de leurs filtrats de culture) apparait comme un exemple nouveau mais voisin d'interactions déjà décrites entre tabac et divers agents biologiques : virus (GIANINAZZI, 1969, 1970), extraits bactériens (GIANINAZZI \& MARTIN, 1975), bactéries (AHL et al., 1981) ou champignon comme Thielaviopsis basicola (GIANINAZZI et al., 1980); dans ce dernier cas, les auteurs regrettent de n'avoir pu comparer une interaction sensible aux 4 interactions donnant des lésions nécrotiques foliaires avec production de protéines b. L'intérêt est donc d'avoir pu comparer et différencier ici, par une production rapide de protéines, l'interaction résistante de l'interaction sensible.

Dans la cinétique comparée d'apparition des protéines b (fig. 3B), 2 points sont à retenir. D'une part, la différence de réponse entre les 2 types d'interaction n'est pas d'ordre qualitatif mais d'ordre quantitatif puisqu'il y a apparition faible et tardive de potéines $b$ chez le couple compatible ; or ce type de protéines a déjà été mis en évidence dans des interactions sensibles tabac-VMT mais tardivement et « au moment où la synthèse virale est en voie d'achèvement " (GIANINAZZI et al., 1980). D'autre part, on aurait dans l'interaction non compatible une décroissance assez rapide du taux de protéines $b$; peu décrit jusqu'à présent, ce phénomène serait à préciser d'autant que, s'il y a corrélation entre présence de ces protéines et induction de résistance, cette dernière ne serait alors que très temporaire.

Chez la variété "Samsun nn ", les résultats obtenus avec les divers Phytophthora (souches et filtrats) sont parallèles à ceux observés sur la variété "Xanthi nc". $\mathrm{La}$ présence de protéines $\mathrm{b}$ dans les interactions Phytophthora non compatibles var. "Samsun nn » confirme, chez cette variété de tabac, sa potentialité de produire de telles protéines déjà décrites dans certains cas d'interactions virales (VAN LOON, 1975a; GIANINAZZI, 1978, 1983). Ce fait souligne la notion de spécificité d'inducteur et peut être rapproché des résultats obtenus avec la variété « Judy's Pride Burley » : absence des protéines $b$ après inoculation par le VMT, présence après inoculation par Thielaviopsis basicola (GIANINAZZI et al., 1980).

Enfin, peut-on assimiler la notion d'incompatibilité des espèces de Phytophthora non pathogènes sur tabac (nécroses foliaires à distance, limitation de l'envahissement caulinaire et production rapide de protéines b) à la notion d'hypersensibilité virale définie dans l'interaction VMT - tabac var. "Xanthi nc"? La similitude paraît se justifier si l'on considère l'invasion limitée et la production de protéines $b$ mais paraît plus discutable au niveau des phénomènes nécrotiques: on ne peut guère assimiler la nécrose d'hypersensibilité entourant l'infection virale aux nécroses foliaires apparaissant à distance du point d'inoculation chez le modèle Phytophthora.

\section{Protection induite vis-à-vis du Phytophthora pathogène}

Bien que préliminaires, les résultats montrent la possibilité d'induire un certain état de protection visà-vis du pathogène par des prétraitements avec divers organismes (ou leurs extraits) tout à la fois non compatibles et inducteurs de protéines $b$. Ceci rejoindrait donc l'induction de résistance par préinoculation de champignons non compatibles (HAMMERSCHMIDT et $a l ., 1976)$ ou de virus à réaction hypersensible (Mc INTYRE \& DODDS, 1979) mais où aucune corrélation n'a été faite avec l'apparition de protéines solubles additionnelles; pour les filtrats de culture, plusieurs ont été décrits comme éliciteurs de phytoalexines (ANDERSON, 1978 ; DE WIT \& ROSEBOOM, 1980) mais, dans certains modèles, l'« immunisation " par divers extraits d'organismes parasites s'est heurtée à des difficultés certaines (KUĆ, 1982). Ces résultats se rapprochent enfin des nombreux exemples de corrélation entre présence de protéines $b$ et induction de résistance (GIANINAZZI \& MARTIN, 1975 ; VAN LOON, $1975 b$, GiANINAZZI et al., 1980) bien qu'elle ne soit pas toujours vérifiée (COUSSIRAT, 1983).

Si les protéines $b$ apparaissent ici comme marqueurs qualitatifs d'un état de protection, on ne peut faire à l'heure actuelle aucune relation entre quantité de protéines $b$ et niveau de résistance : l'effet de protection est comparable avec les 2 filtrats F. 147 et F. 195 (fig. 4A) qui donnent des quantités de protéines b différentes (respectivement 41,8 et 14,8-tabl. 1A).

En conclusion trois ensembles de questions se posent :

1) Par purification d'un filtrat de culture brut d'une espèce non compatible peut-on séparer ou non différentes fractions respectivement inductrices de résistance, de protéines $b$ et de symptômes nécrotiques ? La réponse pourrait orienter le choix - parmi divers inducteurs possibles - vers des filtrats (ou fractions de filtrat) à effet protecteur (et inducteurs de protéines $b$ ?) mais dépourvus d'action nécrosante préjudiciable au devenir de la plante.

2) Peut-on préciser l'induction de protection quant à son intensité et à son efficacité dans l'espace (protection localisée ou systémique avec induction possible jusqu'au niveau racinaire ?) et dans le temps (persistance de l'effet protecteur?).

3) La réaction typique d'hypersensibilité virale peut-elle être assimilée à l'interaction fongique incompatible ? La notion de " toxine(s) d'incompatibilité ", déclenchant un état de résistance non spécifique chez la plante et limitant la progression de l'agresseur, peut-elle être une voie d'approche dans les mécanismes de spécialisation parasitaire?

Reçu le 21 février 1986. Accepté le 18 juin 1986 


\section{RÉFÉRENCES BIBLIOGRAPHIQUES}

Abad P., Poupet A., Ponchet M., Venard P., Bettachini B., 1985. Separation and quantitative assay of three pathogenesis-related (b) proteins from tobacco mosaic virus hypersensitive Nicotiana tabacum by reversed-phase high-performance liquid chromatography. $J$. Chromatogr., 318, 417-426.

Ahl P., 1983. Aspect génétique et moléculaire de la résistance (réaction d'hypersensibilité) chez les Nicotiana. Thèse Université Genève, $123 \mathrm{p}$.

Ahl P., Benjama A., Samson R., Gianinazzi S., 1981. Induction chez le tabac par Pseudomonas syringae de nouvelles protéines (protéines $《 b \gg$ associées au développement d'une résistance non spécifique à une deuxième infection. Phytopathol. Z., 102, 201-212.

Anderson A. J., 1978. Isolation from three species of Colletotrichum of glucan-containing polysaccharides that elicit browning and phytoalexin production in bean. Phytopathology, 68, 189-194.

Antoniw J. F., Pierpoint W. S., 1978. The purification and properties of one of the $4 \mathrm{~b}$ " proteins from virus-infected tobacco plants. J. Gen. Virol., 39, 343-350.

Antoniw J. F., Ritter C. E., Pierpoint W. S., Van Loon L. C., 1980. Comparison of three pathogenesis-related proteins from plants of two cultivars of tobacco infected with TMV. J. Gen. Virol., 47, 79-87.

Bonnet Ph., 1985. Réactions différentielles du tabac à 9 espèces de Phytophthora. Agronomie, 5 (9), 801-807.

Coussirat J. C., 1983. Induction of soluble (b) proteins by Peronospora tabacina in Nicotianae treated with polyacrylic acid or fungicides and in untreated Nicotianae. Neth. J. Plant Pathol., 89, 321.

Devergne J. C., Cardin L., 1967. Utilisation de la réaction sérologique en immunodiffusion comme test de diagnostic du virus du "Mottle " de l'œillet. Ann. Epiphyt., 18, N HS, 85-103.

Gianinazzi S., 1978. Does the hypersensitive reaction in tobacco require the gene $\mathrm{N}$ ? 3rd Int. Congr. Plant Pathol., München 16-23, August 1978, p. 222.

Gianinazzi S., 1983. The genetic and molecular basis of b-proteins in the genus Nicotiana. Neth J. Plant Pathol., 89, 275-281.

Gianinazzi S., Martin C., 1975. A naturally occuring active factor inducing resistance to virus infection in plants. Phytopathol. Z., 83, 23-26.

Gianinazzi S., Vallée J. C., Martin C., 1969. Hypersensibilité aux virus, température et protéines solubles chez le Nicotiana Xanthi n.c. C.R. Acad. Sci., Paris, 268, 800-802.

Gianinazzi S., Martin C., Vallée J. C., 1970. Hypersensibilité aux virus, température et protéines solubles chez le Nicotiana Xanthi n.c. Apparition de nouvelles macro-molécules lors de la répression de la synthèse virale. C.R. Acad. Sci., Paris, 270 D, 2383-2386.

Gianinazzi S., Pratt H. M., Shewry P. R., Miflin B. J., 1977. Partial purification and preliminary characterization of soluble leaf proteins specific to virus-infected tobacco plants. J. Gen. Virol., 34. 345-351.

Gianinazzi S., Ahl P., Cornu A.. Scalla R., 1980. First report of host $\mathrm{b}$-protein appearance in response to a fungal infection in tobacco. Physiol. Plant pathol, 16. 337-342.

Hammerschmidt S., Acres S., Kuć J., 1976. Protection of cucumber against. Colletotrichum lagenarium by Colletotrichum lagenarium. num. Phytopathology, 66, 790-793.

Kuć J., 1982. Plant immunization mechanisms and practical implications, 157-177. In R. K. S. WOOD : "Active defense mechanisms in plants », $381 \mathrm{p}$.

Kuć J., Shockley G., Kearney K., 1975. Protection of cucumber against. Colletotrichum lagenarium by Cladosporium lagenarium. Physiol. Plant Pathol., 7, 195-199.

Mc Intyre J. L.., Dodds J. A., 1979. Induction of localized and systemic protection against Phytophthora parasitica var. nicotianae by tobacco mosaic virus infection to tobacco hypersensitive to the virus. Physiol. Plant Pathol., 15, 321-330.

Plich M., Rudnicki R. M., 1979. Studies of the toxins of Phytophthora cactorum pathogenic to apple trees. I. Isolation, some of the properties and activities of a toxin produced by the fungus cultured in vitro. Phytopathol. Z., 94, 270-278.

Ross A. F., 1961. Localized acquired resistance to plant virus infection in hypersensitive hosts. Systemic acquired resistance induced by localized virus infections in plants. Virology, 14, 329-339; 340-358. Rossignol M., 1979. La prémunition des plants de melon contre l'anthracnose. Approches physiologiques du phénomène. Thèse Université P. Sabatier, Toulouse, 63 p.

Van Loon L. C., 1975a. Polyacrylamide dise electrophoresis of the soluble leaf proteins from Nicotiana tabacum var. "Samsun " and "Samsun NN". III. Influence of temperature and virus strain on changes induced by tobacco mosaic virus. Physiol. Plant Pathol., 6, 289-300.

Van Loon L. C., 1975b. Polyacrylamide disc electrophoresis of the soluble leaf proteins from Nicotiana tabacum var. "Samsun " and "Samsun NN" IV. Similitary of qualitative changes of specific proteins after infection with different viruses and their relationship to acquired resistance. Virology, 67, 566-575.

Van Loon L. C., Van Kammen A., 1970. Polyacrylamide disc electrophoresis of the soluble leaf proteins from Nicotiana tabacum var. Xanthi and Samsun NN. II changes in protein constitution after infection with tobacco mosaic virus. Virologv, 40, 199-211.

De Wit P. J. G. M., Roseboom P. H. M., 1980. Isolation, partial characterization and specificity of glycoprotein elicitors from culture filtrates, mycelium and cell walls of Cladosporium fulvum (Syn. Fulvia fulvia). Physiol. Plant Pathol., 16, 391-408. 